\title{
Thermogravimetric Studies on Non-isothermal Oxidative Pyrolysis of Lignocellulosic Materials
}

\author{
VIJU KUMAR V. G. \\ Department of Chemistry, University College, Thiruvananthapuram, Kerala-695034, India. \\ *Corresponding author E-mail: vgviju@ gmail.com \\ http://dx.doi.org/10.13005/ojc/360421
}

(Received: July 20, 2020; Accepted: August 25, 2020)

\begin{abstract}
Inter species variations of lignocellulosic fibres were investigated in terms of the thermal degradation behaviour of ten different bamboo species using simultaneous TG-DTA analysis. The pyrolysis profiles under oxidative atmosphere shows that the thermal stability based on first stage of degradation is lowest for bambusa vulgaris and higher stability is attributed to dendrocalamus strictus and dendrocalamus membranaceus. The threshold temperature for active biomass pyrolysis for the first mass loss stage is between $220^{\circ} \mathrm{C}-240^{\circ} \mathrm{C}$. Dendrocalamus membranaceus, Bambusa nutans and Bambusa vulgaris complete the decomposition process in two distinct stages and all others in three stages. The first stage, dominant below $340^{\circ} \mathrm{C}$, degrades polymeric chains forming active carbonaceous char which release volatile gases upon increase in temperature and $\sim 5 \%$ by weight of char remains above $450^{\circ} \mathrm{C}$. The kinetic parameters of the solid state reactions were calculated using the Coats-Redfern integral method and are found to be highest for Bambusa vulgaris. The activation energy for the major mass loss stage in decomposition profiles ranges from 153.0 to 226.9 $\mathrm{kJ} \mathrm{mol}^{-1}$. The stability in terms of DTG peak temperature is highest for dendrocalamus strictus, which possess the lowest values for kinetic parameters for the main decomposition stage. For the second stage, values of the kinetic parameters are found to be maximum for Bambusa vulgaris and the lowest for Bambusa nutans. Solid state kinetics were found to obey Mampel equation comprising the mechanism of random nucleation with single nucleus on each particle.
\end{abstract}

Keywords: Lignocellulosic biomass, Bamboo, Thermogravimetry, Coats-Redfern, Pyrolysis, Kinetics.

\section{INTRODUCTION}

Bamboo is a versatile, fast growing and renewable non-timber forest product which grows in comparatively hot and humid climates of subtropical and temperate zones of various parts of earth. Undesirable consequences of population growth in countries like India, demands sustainable and biodegradable materials for daily applications and where bamboo comes in to play. Despite of its environmental importance and as a bioenergy feedstock, wide varieties of industrial applications of bamboo have been put forward by researchers such as rayon, plywood, reinforced boards, laminated flooring and food. High-performance adhesives and fiber engineering can be employed for durable lignocellulosic composites with high strength. Lignocellulosic biomass can also be incorporated

This is an Open Access article licensed under a Creative Commons license: Attribution 4.0 International (CC- BY). Published by Oriental Scientific Publishing Company @ 2018 
with plastics, glass, metals and synthetic compounds to manufacture diverse products. It is possible to combine more than one materials in a synergic way so that a new engineering system can be evolved which is better than the constituent components with enhanced dimensional stability ${ }^{1}$.

The studies reveal that the bamboo consists of holocellulose $(60-70 \%)$, cellulose (26$43 \%$ ), hemicellulose and lignin (each amounted to about $20-30 \%)$, pentosans (20-25\%), ash (1.7-5\%), silica $(\sim 0.7 \%)$ and minor constituents like resins, tannins, waxes and trace amounts of inorganic salts. The composition of bamboo culm are comparable to that of common hardwood, but with greater alkaline extract, silica and ash contents ${ }^{2}$. Lignocellulosic materials decompose thermally by two different mechanisms irrespective of the variations in their composition. The first mechanism, often found below $300^{\circ} \mathrm{C}$ is associated with breakage of polymeric chains by bond fission, dehydration, formation of free radicals, carbonyl, carboxyl and hydroperoxide groups and release of gases such as $\mathrm{CO}$ and $\mathrm{CO}_{2}$. Finally the reactive carbonaceous char is yielded. Oxidation of the carbonaceous char and combustible volatile gasses leads to smoldering combustion and flaming combustion respectively ${ }^{3,4}$. The second mechanistic pathway, which operates above $300^{\circ} \mathrm{C}$, mainly consists of the fission of secondary bonds leading to some intermediate systems such as anhydromonosaccharides, which degrades into smaller systems, giving carbonized products ${ }^{5}$. Temperature beyond $450^{\circ} \mathrm{C}$, the char is predominant, and further decomposition results in the formation of volatiles and is designated as afterglow. The rate of formation of carbonaceous char decreases and tar forming reactions increases above $300^{\circ} \mathrm{C}$. The tar comprises of anhydro sugar derivatives which hydrolyses to reducing sugars. Levoglucosan and other volatile products evaporates in endothermic reaction which is followed by the exothermic combustion reactions ${ }^{6}$.

The high percentage of volatiles is released from cellulose, which possess lowest heat of combustion and char yield. The whole wood releases next level of volatiles with higher heat of combustion and percentage of char formation. Bark exhibits higher heat of combustion as compared to wood with a high char and volatiles yield. Heat of combustion of lignin is the highest, giving out maximum char yield and the lowest yield of volatiles ${ }^{4}$.
Several researchers focused on the thermal behaviour of industrially useful wood species. But the thermal decomposition characteristics of bamboo species are less studied and not compared among species and the field is yet to be explored. Wiedemann studied the wood components in relation to the growth period of a tree using different thermoanalytical techniques ${ }^{7}$. The composition of the stem varies according to the age, climate, soil constitution etc. So in order to make the study more scientific and reproducible, the bamboo samples were received from the bamboo plantation of JNTBGRI Thiruvananthapuram, India and the ten species of bamboo trees were of more or less same age and growing in the same terrain with similar growing conditions. The main objectives of this study is to increase the knowledge of the complex chemical mechanisms involved in the thermal degradation of lignocellulosic biomass giving special attention to ten varieties of bamboo. Such a comparison is not made elsewhere till the date.

\section{MATERIALS AND METHODS}

The present investigation aims to assess the thermal stability of ten species of bamboo such as Cephalostachyum pergracile, Bambusa pallida, Dendrocalamus brandisii, Dendrocalamus strictus, Dendrocalamus hamiltoni, Dendrocalamus gigantus, Dendrocalamus membranaceus, Bambusa nutans, Bambusa bambos and Bambusa vulgaris. The ten varieties of bamboo are approximately five years of age and all are cultivated in identical climate and soil conditions. The bamboo samples are collected from approximately three feet above the ground level of plant. The mode of preparation to obtain samples of each bamboo species is as follows. bamboo culms were split into pieces of $2.5 \mathrm{~cm}$ wide using a chisel. They were cut into small pieces about $8.0 \mathrm{~cm}$ long for the milling process. The separated bamboo strips were kept in water for 48 and then strips were removed and sliced longitudinally to extract the fibres. The clean samples are air dried at ambient laboratory conditions for approximately 10 days. Milling and homogenization was done to minimise the errors of thermal analysis procedure and get an average of each system. Bamboo samples were milled by a standard Whiley mill with a screen of $2 \mathrm{~mm}$. Sieving was performed so as to get powder, approximately 40 (400 microns) - 60 (250 microns) mesh size (American Standard ASTM - E 11). Small 
particle size is preferred to check serious mass and heat transfer limitations. The wood powder (approximately $500 \mathrm{mg}$ ) of ten varieties of bamboo are separately treated in $10 \mathrm{~mL}$ distilled water, stirred and maintained at room condition for forty eight hours and oven dried at $70^{\circ} \mathrm{C}$.

The thermogravimetric analysis (TGA) was conducted in a Mettler Toledo thermal analyser. A linear heating rate of $10 \mathrm{~K} \mathrm{~min}^{-1}$ in dry dynamic air with a consistent flow rate $\left(60 \mathrm{mLmin}^{-1}\right)$ is employed for all the samples in the temperature range of ambient to $\sim 800^{\circ} \mathrm{C}$. For the interpretation of thermal behaviour, the data obtained from the TG, DTG (derivative thermogravimetry) and DTA (differential thermal analysis) experiments were used. Thermal decomposition kinetics and mechanism of samples were also investigated using these data.

\section{RESULTS AND DISCUSSION}

\section{Phenomenological studies of different bamboo species}

The TG, DTG and DTA profiles of all the ten varieties of bamboo have been presented in Fig. 1 to 10. The data of the phenomenological aspects for the ten species of bamboo are tabulated in Table 1.

Since lignocellulosic material is a heterogeneous mixture of various constituent compounds, different fractions decompose at different temperature regimes. Maximum pyrolyzable fraction is attributed to biomass at a given temperature, independent of the time. So we depend upon global mass loss kinetics. Global kinetics can be extended for modeling complex solid state decomposition reactions where the complete spectrum of the hydrocarbon decomposition reactions are irrelevant. Global pyrolysis kinetics applied to bamboo is used to previse the overall rate of mass loss from the sample. Even if so many volatile products are discharged during decomposition, global kinetics shine light upon the key mechanistic stages in the overall decomposition process.

All the bamboo samples show a very small mass loss at $70-110^{\circ} \mathrm{C}$ and are due to desorption of moisture. In the case of $\mathrm{CP}$, mass loss of $3.3 \%$ is observed below $\sim 110^{\circ} \mathrm{C}$ (Fig. 1). Before the active mass loss starts, small endothermic peak or region is found and is due to the melting or softening of waxy constituents in the sample. The threshold temperature for active wood pyrolysis for the bamboo species, CP is observed at $230^{\circ} \mathrm{C}$. All the samples exhibit the onset temperature for the first mass loss stage in between $220-240^{\circ} \mathrm{C}$. Except DM, BN and $\mathrm{BV}$ all other species undergo decomposition in three stages, and $\mathrm{DM}, \mathrm{BN}$ and $\mathrm{BV}$ complete the decomposition process in two distinct stages.

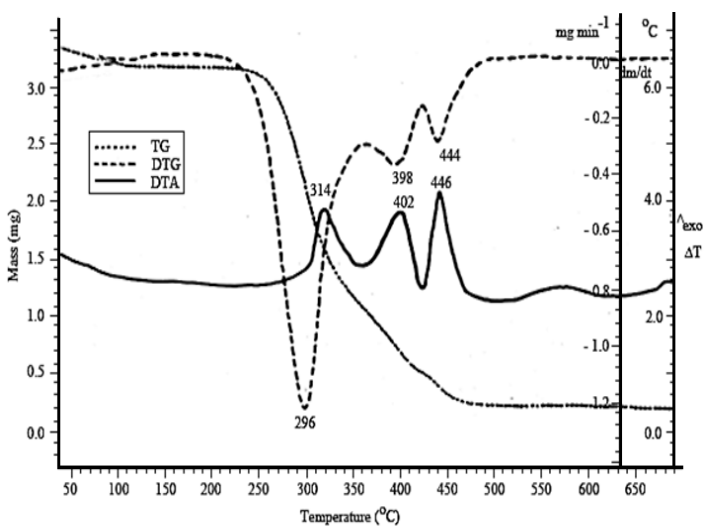

Fig. 1.TG-DTA profile of CP

The sample of CP shows three DTG peaks with maxima at 296,398 and $444^{\circ} \mathrm{C}$. The largest DTG curve is found for the first decomposition stage. Hemicellulose and lignin fractions are degraded in the temperature regime $200-300^{\circ} \mathrm{C}$ and $225-450^{\circ} \mathrm{C}$, respectively. Dehydration reactions above $200^{\circ} \mathrm{C}$ are responsible for the decomposition of hemicellulose and lignin which produce high char quantity. Thermal degradation of cellulose can also be accelerated in presence of acids and oxygen. Volatilisation of laevoglucosan from cellulose is probably involved in the first stage of decomposition.

Of the three major lignocellulosic components, lignin fraction starts decomposing at lower temperature $\left(160-170^{\circ} \mathrm{C}\right)$. But the pyrolysis happens in an extensive temperature range with relatively low rates until $\sim 900^{\circ} \mathrm{C}$. So, in the decomposition of biomass materials, lignin is mainly responsible for char production. Since hemicellulose also starts decomposing at lower temperatures compared to cellulose, it makes an appreciable contribution to the formation of char. Sharp exothermic DTA peaks are found at 314 , 402 and $446^{\circ} \mathrm{C}$. For the first stage, especially, in the range from the commencement of the reaction to maximum mass loss rate, oxidation is weakly exothermic as evident by the difference between the DTG peak $\left(296^{\circ} \mathrm{C}\right)$ and DTA maximum $\left(314^{\circ} \mathrm{C}\right)$. 
In presence of air, the flaming of volatiles precedes, and produces high amount of heat than the glowing of solid residue. Since an oxidative atmosphere is maintained, the initial endothermic pyrolysis reaction is superimposed by strong exothermic oxidation. For the second and third stages the DTG maxima coincide with the corresponding DTA peaks. This indicates that the point of maximum mass loss rate is associated with the decomposition and oxidative gasification of char which is highly exothermic in nature. The sample of $\mathrm{CP}$ gives a char residue of $29.5 \%$ at the end set of the primary stage of pyrolysis. Approximately $67 \%$ of the lignocellulosic material excluding the initial moisture content was lost as volatiles in the oxidative atmosphere below $\sim 360^{\circ} \mathrm{C}$. In the temperature range $240-360^{\circ} \mathrm{C}$, cellulose and hemicellulose fractions of bamboo are somewhat completely consumed. Above $410^{\circ} \mathrm{C}$, the mass loss rate is decreased and tends to reach constant mass. The major biomass components are almost completely decomposed below the final DTG peak commences and $11 \%$ of the sample remains at this point, which is stable char containing minor amounts of lignin, ash and decomposition products of cellulose and hemicellulose. The third stage of decomposition is indicated by the narrow DTG peak width of $430-460^{\circ} \mathrm{C}$ and a mass loss of $5.0 \%$ is observed for this stage. The exothermic peak towards the end of the decomposition process is due the glowing combustion of high molecular weight chars and decomposition is complete at $\sim 480^{\circ} \mathrm{C}$ leaving char residue of $4.2 \%$. The similar observations were shown by Amutio et al., in the oxidative pyrolysis of the bamboo species, where devolatization and char combustion occurs in the range $209-315^{\circ} \mathrm{C}$ and $315-333^{\circ} \mathrm{C}$ respectively ${ }^{8}$. Compared to inert atmosphere, the oxidizing atmosphere accelerates the devolatilization process. In thermogram, a peak which ends at a lower temperature has a shoulder due to char combustion. In the thermogram of forest pinewood waste, the main peak ends at lower temperature and another second peak is found at higher temperature. Lu and Chen pointed out similar results in another experiment involving bamboo species ${ }^{9}$.

Table 1: Phenomenological data for the thermal decomposition of ten bamboo species

\begin{tabular}{|c|c|c|c|c|c|c|c|}
\hline \multirow[b]{2}{*}{ Sample } & \multicolumn{5}{|c|}{ (mass $\sim 3 \mathrm{mg}, \phi=10^{\circ} \mathrm{C} \mathrm{min}^{-1}$, atmosphere $=$ dynamic air) } & \multirow[b]{2}{*}{$\begin{array}{l}\text { Peak width } \\
\text { in DTA }\left({ }^{\circ} \mathrm{C}\right)\end{array}$} & \multirow[b]{2}{*}{ Residue } \\
\hline & $\begin{array}{l}\text { Plateau in } \\
\text { TG }\left({ }^{\circ} \mathrm{C}\right)\end{array}$ & Stage & $\begin{array}{l}\text { Peak temperature } \\
\text { in DTG }\left({ }^{\circ} \mathrm{C}\right)\end{array}$ & $\begin{array}{l}\text { Peak width } \\
\text { in DTG }\left({ }^{\circ} \mathrm{C}\right)\end{array}$ & $\begin{array}{l}\text { Peak temperature } \\
\text { in DTA }\left({ }^{\circ} \mathrm{C}\right)\end{array}$ & & \\
\hline \multirow[t]{3}{*}{ Cephalostachyum pergracile } & Up to 230 & 1 & 296 & $250-320$ & 314 & $300-320$ & 29.5 \\
\hline & & II & 398 & $370-420$ & 402 & $380-420$ & \\
\hline & After 480 & III & 444 & $440-460$ & 446 & $430-460$ & 4.2 \\
\hline \multirow[t]{3}{*}{ Bambusa pallida } & Up to 240 & 1 & 278 & $240-310$ & 312 & $280-330$ & 32.3 \\
\hline & & II & 398 & $380-430$ & 404 & $380-430$ & \\
\hline & After 480 & III & 450 & $430-470$ & 457 & $430-490$ & 6.5 \\
\hline \multirow[t]{3}{*}{ Dendrocalamus brandisii } & Up to 230 & I & 286 & $240-320$ & 312 & $280-350$ & 33.3 \\
\hline & & II & 409 & $380-420$ & 413 & $380-440$ & \\
\hline & After 470 & III & 452 & $440-460$ & 458 & $440-480$ & 4.3 \\
\hline \multirow[t]{3}{*}{ Dendrocalamus strictus } & Up to 240 & 1 & 323 & $290-340$ & 334 & $320-360$ & 39.7 \\
\hline & & II & 434 & $400-450$ & 437 & $410-440$ & \\
\hline & After 470 & III & 463 & $460-480$ & 466 & $450-470$ & 3.8 \\
\hline \multirow[t]{3}{*}{ Dendrocalamus hamiltoni } & Up to 240 & 1 & 289 & $250-320$ & 319 & $280-340$ & 40.9 \\
\hline & & II & 414 & $370-430$ & 418 & $380-420$ & \\
\hline & After 480 & III & 456 & $440-470$ & 459 & $440-470$ & 5.5 \\
\hline \multirow[t]{3}{*}{ Dendrocalamus gigantus } & Up to 220 & I & 289 & $250-320$ & 314 & $280-340$ & 38.1 \\
\hline & & II & 402 & $380-420$ & 408 & $380-430$ & \\
\hline & After 470 & III & 448 & $430-460$ & 449 & $440-470$ & 7.5 \\
\hline \multirow[t]{2}{*}{ Dendrocalamus membranaceus } & Up to 240 & 1 & 323 & $290-340$ & 333 & $310-360$ & 38 \\
\hline & After 450 & II & 436 & $410-450$ & 446 & $430-450$ & 4.7 \\
\hline \multirow[t]{3}{*}{ Bambusa nutans } & Up to 240 & I & 321 & $290-330$ & 321 & $300-370$ & 35.8 \\
\hline & After 460 & II & 426 & $390-430$ & 436 & $420-440$ & \\
\hline & & III & - & $430-450$ & 456 & $440-460$ & 3.8 \\
\hline \multirow[t]{3}{*}{ Bambusa bambos } & Up to 240 & 1 & 320 & $290-330$ & 331 & $300-350$ & 39.9 \\
\hline & & II & 424 & $390-430$ & 427 & $390-430$ & \\
\hline & After 490 & III & 457 & $430-460$ & 458 & $450-470$ & 4.7 \\
\hline \multirow[t]{2}{*}{ Bambusa vulgaris } & Up to 220 & 1 & 276 & $260-310$ & 306 & $260-320$ & 34.4 \\
\hline & After 470 & II & 441 & $410-450$ & 443 & $420-470$ & 8.5 \\
\hline
\end{tabular}


The sample of BP shows no significant loss of mass till $\sim 220^{\circ} \mathrm{C}$, and thereafter, it decomposes in three stages designated by DTG maxima at 278, 398 and $450^{\circ} \mathrm{C}$ (Fig. 2). The peak temperature of main decomposition stage for $\mathrm{BP}$ is reduced by $18^{\circ} \mathrm{C}$ compared to main stage decomposition of CP. It is due to the varying chemical composition of hemicellulose and cellulose. Since hemicellulose starts decomposing at much lower temperature than cellulose does, its higher percentage of former may shift DTG peak temperature to lower value. But for the second stage, both $\mathrm{CP}$ and BP show the same DTG peak temperature. After the main decomposition stage the residue remains is $32.3 \%$ and after the final stage it is $6.5 \%$. BP shows constant mass after $\sim 500^{\circ} \mathrm{C}$.

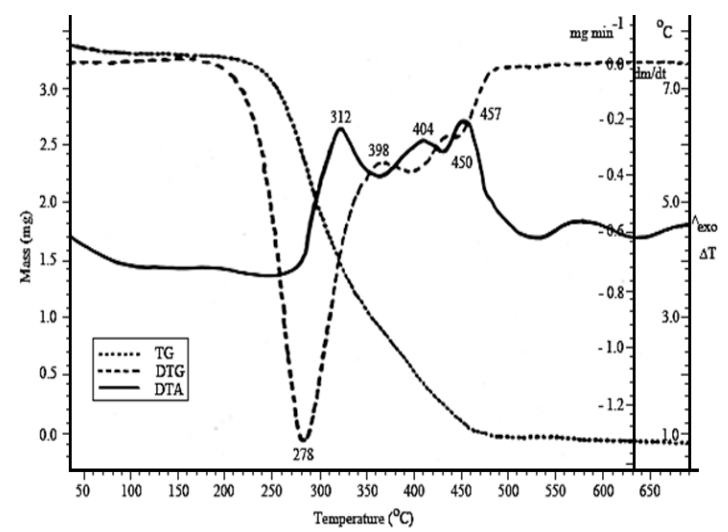

Fig. 2. TG-DTA profile of BP

The species, DB is stable up to $\sim 220^{\circ} \mathrm{C}$ (Fig. 3). DB decomposes in three stages as indicated by the DTG peaks at 286,409 and $452^{\circ} \mathrm{C}$ and the corresponding exothermic DTA peaks at 312 , 413 and $455^{\circ} \mathrm{C}$. The first and second DTA peaks are spaced by temperature difference of $101^{\circ} \mathrm{C}$ for DB indicating that the char residue obtained at the end set of the first stage of decomposition resists oxidative gasification. But for $\mathrm{CP}$ and $\mathrm{BP}$ it was nearly $90^{\circ} \mathrm{C}$ indicating that the residue formed is comparatively more susceptible to oxidation or decomposition to volatiles. The residue remained after the first and third stages are 33.3 and $4.3 \%$, respectively. The sample of DB attains a constant mass after $\sim 470^{\circ} \mathrm{C}$.

The sample of DS exhibits no significant mass loss up to $\sim 240^{\circ} \mathrm{C}$ except small mass loss of $3.2 \%$ below $110^{\circ} \mathrm{C}$ due to desorption of moisture (Fig. 4). The three stages of thermal decomposition are denoted by the DTG maxima at 323, 434 and $463^{\circ} \mathrm{C}$. The shoulder near $\sim 300^{\circ} \mathrm{C}$ at left hand side of the first DTG peak corresponds to the hemicellulose decomposition which commences at $\sim 200^{\circ} \mathrm{C}$. This region corresponds to broad endothermic region in the DTA curve. The spacing between the first and second DTG maxima is about $111^{\circ} \mathrm{C}$ indicating the thermal stability of the residue formed at the end set of the first stage. A high char yield of $39.7 \%$ is observed after the first stage. The second stage of decomposition is denoted by exothermic DTA peak at $434^{\circ} \mathrm{C}$. The final stage is indicated by a small exothermic DTA peak at $466^{\circ} \mathrm{C}$.

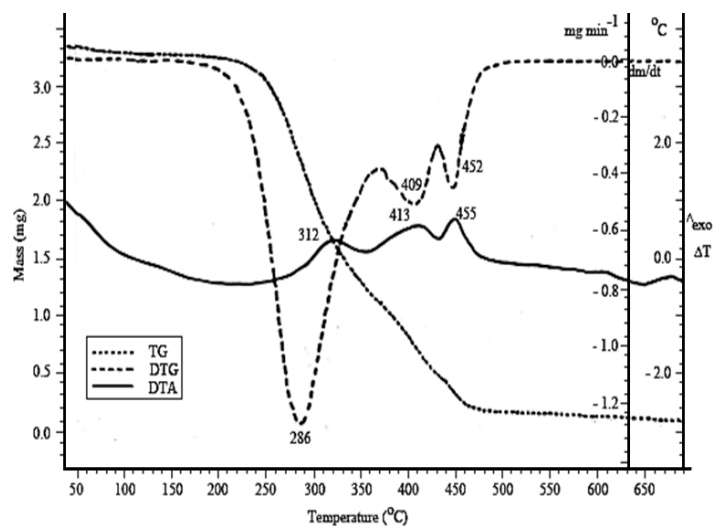

Fig. 3. TG-DTA profile of DB

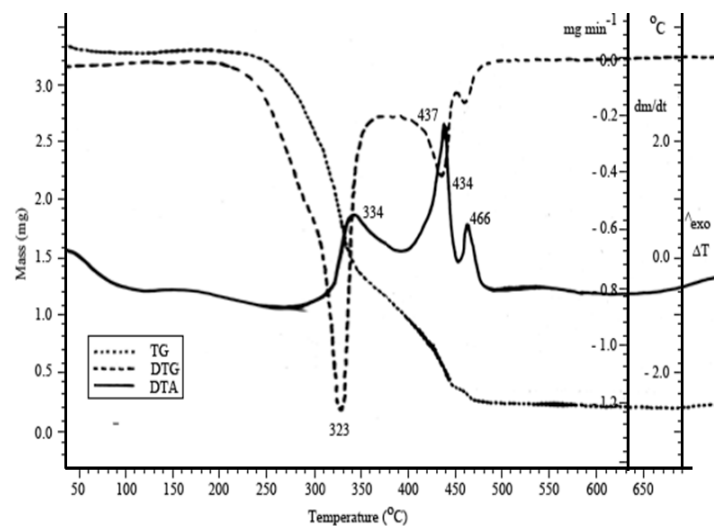

Fig. 4. TG-DTA profile of DS

The sample of $\mathrm{DH}$ is stable up to $\sim 220^{\circ} \mathrm{C}$ with no significant mass loss (vide Fig. 5). The three decomposition stages are indicated by DTG peaks at 289,414 and $456^{\circ} \mathrm{C}$ and corresponding exothermic DTA maxima at 319,418 , and $459^{\circ} \mathrm{C}$. The major DTG peaks are separated by $125^{\circ} \mathrm{C}$ showing the stability of the residue formed after the first stage. The residue left after the first stage is $40.9 \%$.

Like $\mathrm{DH}$, the bamboo species $\mathrm{DG}$ is also stable up to $\sim 220^{\circ} \mathrm{C}$ and decomposes thereafter (Fig. 6). Both DH and DG show constant mass after $\sim 470^{\circ} \mathrm{C}$. The sample of DM undergoes decomposition 
in two stages indicated by DTG peaks at 323 and $436^{\circ} \mathrm{C}$, respectively (Fig. 7) with two sharp exothermic peaks at 333 and $446^{\circ} \mathrm{C}$. After the first decomposition stage the DTA profile shows a shoulder and is due to the decomposition of cellulose. The lignin undergoes endothermic fragmentation, but it is masked by strong exothermic process of char formation and oxidative reactions. The sample of BN (Fig. 8) also shows similar phenomenological data as that of BB (Fig. 9). The samples DS, DM, BN and BB show a shoulder near $300^{\circ} \mathrm{C}$ and all the four samples shows the first DTG peak with maximum mass loss rate in the narrow range of $320-323^{\circ} \mathrm{C}$. The shoulder is due to the decomposition of hemicellulose as mentioned earlier. All other samples of bamboo without unique shoulder in DTG profile show DTG peak temperature $\leq 296^{\circ} \mathrm{C}$. The pyrolysis of biomass involves early decomposition of hemicellulose (commences $\sim 200^{\circ} \mathrm{C}$ ), followed by pyrolysis of lignin and depolymerization of cellulose. The nature and amount of compounds formed during the decomposition of hemicellulose affects the decomposition mechanism of cellulose and lignin and trigger a set of simultaneous and consecutive reactions which pushes the peak to a higher temperature.

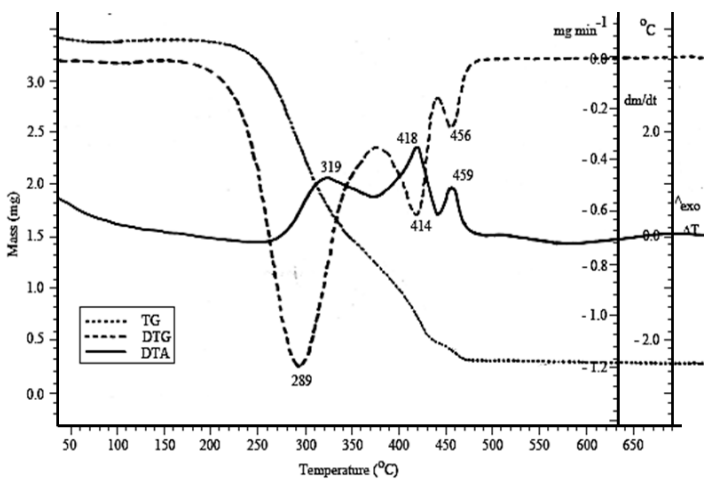

Fig. 5. TG-DTA profile of DH

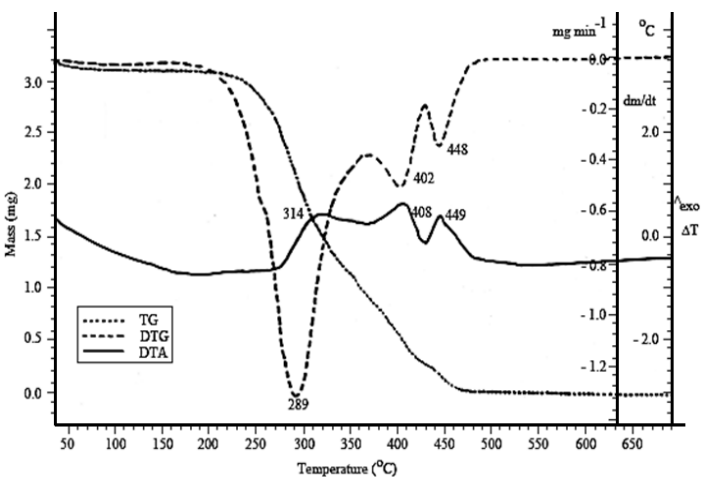

Fig. 6. TG-DTA profile of DG

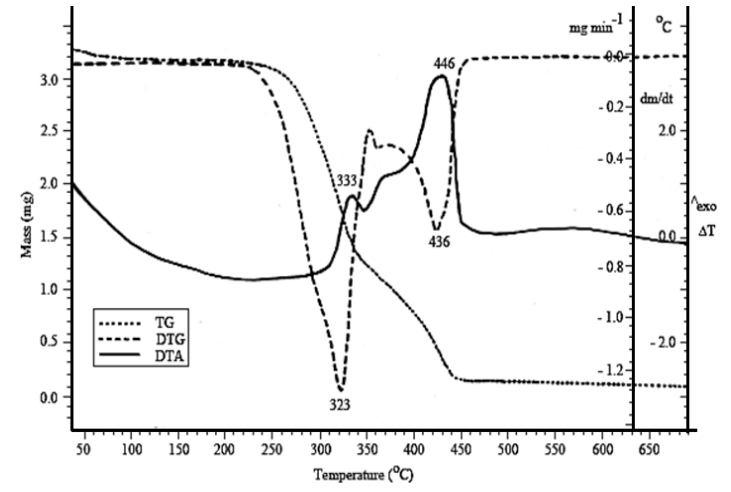

Fig. 7. TG-DTA profile of DM

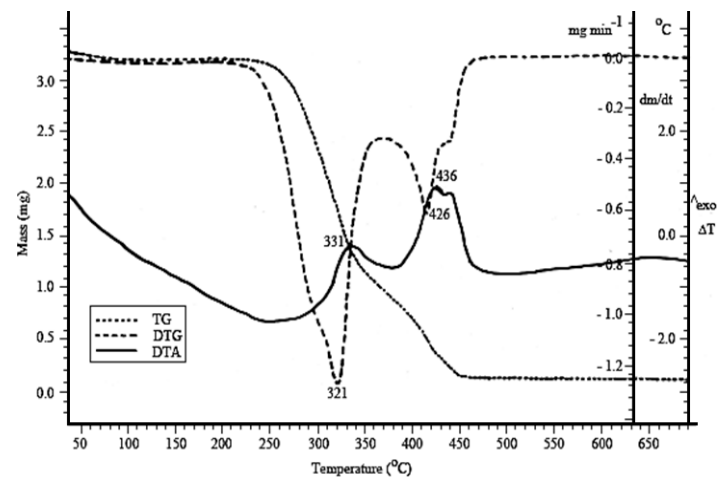

Fig. 8. TG-DTA profile of BN

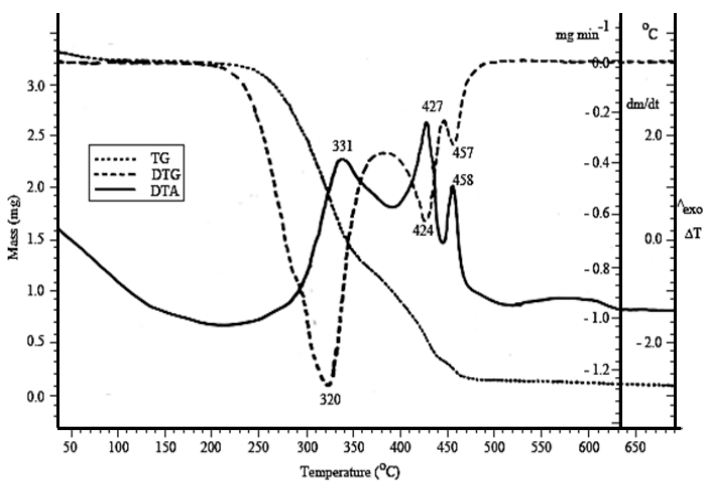

Fig. 9. TG-DTA profile of BB

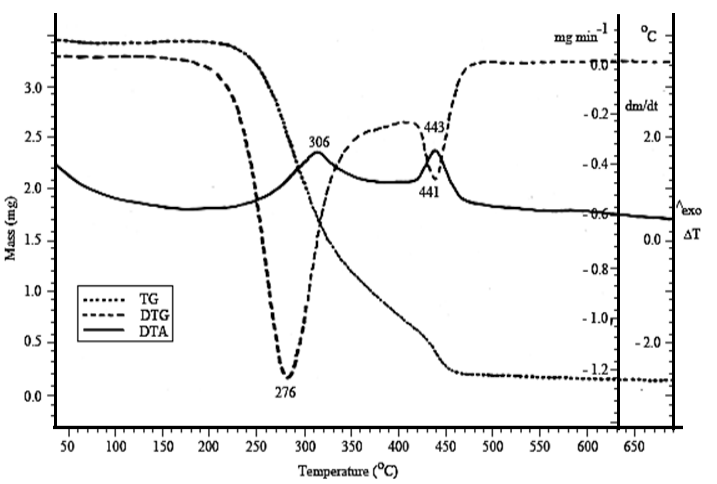

Fig. 10. TG-DTA profile of BV 
Apart from all other samples of bamboo, BV shows two well defined stages of decomposition as shown in Fig. 10. The sample of BV is stable up to $\sim 220^{\circ} \mathrm{C}$. The first stage of decomposition is denoted by a large DTG peak at $276^{\circ} \mathrm{C}$. This sample gives the lowest DTG peak temperature among the ten bamboo species studied. The DTA peak temperature is observed at $306^{\circ} \mathrm{C}$. For the first stage, especially in the range from commencement of reaction to maximum rate of weight loss, oxidation is weakly exothermic, indicated by the difference between DTG peak $\left(276^{\circ} \mathrm{C}\right)$ and DTA maximum $\left(306^{\circ} \mathrm{C}\right)$. Towards the end of first stage, the reactions are found to be highly exothermic. After the first stage, the sample loses mass in a slow manner. The second stage is indicated by DTG peak at $441^{\circ} \mathrm{C}$ and the process is exothermic which is evident from sharp DTA peak at $443^{\circ} \mathrm{C}$. This result is in tune with the observations made by $\mathrm{Bada}^{10}$. Bada proved that the bamboo variety (Bambusa multiplex) with the highest volatile matter has the lowest ignition temperature.
Kinetic Studies of different bamboo species

Solid state thermal decomposition reactions are often quite complex. Keeping the particle size of sample very small for TG analysis ignores heat transfer and diffusion process. The purging of gas in analyzer dissipates the volatile components instantly. So thermal decomposition process is deemed to be an irreversible reaction and fits the first order parallel reaction model. Zehui Jiang and coworkers found that the Coats-Redfern method is useful in determining the kinetic parameters of Moso bamboo pyrolysis ${ }^{11}$. The kinetic parameters of the thermal degradation reactions of the ten bamboo samples were calculated by the CoatsRedfern integral method for each TG curve obtained at $10 \mathrm{~K} \mathrm{~min}^{-1}$ in present investigation ${ }^{12}$. The kinetic parameters including order parameter, correlation coefficient, activation energy, pre-exponential factor and entropy of activation were evaluated for all the thermal decomposition stages ${ }^{13}$. These values are tabulated and presented in Table 2.

Table 2. Kinetic parameters for the thermal decomposition of ten bamboo species

\begin{tabular}{|c|c|c|c|c|c|c|}
\hline Sample & Stage & $\begin{array}{l}\text { Integral method/ } \\
\text { Mechanism }\end{array}$ & $\begin{array}{l}\text { Activation Energy, } \\
\qquad \mathrm{E}\left(\mathrm{kJ} \mathrm{mol}^{-1}\right)\end{array}$ & $\begin{array}{l}\text { Pre-exponential } \\
\text { factor, } A\left(\mathrm{~s}^{-1}\right)\end{array}$ & $\begin{array}{l}\text { Entropy of activation } \\
\qquad \Delta \mathrm{S}(\mathrm{J} \mathrm{K}-1 \mathrm{~mol}-1)\end{array}$ & $\begin{array}{l}\text { Corr. } \\
\text { Coeff. } r\end{array}$ \\
\hline \multirow[t]{4}{*}{ Cephalostachyum pergracile } & \multirow[t]{2}{*}{1} & Coats-Redfern; $n=1.8$ & 192.1 & $7.5 \times 10^{15}$ & 53.6 & 0.9983 \\
\hline & & Random nucleation & 145.5 & $1.6 \times 10^{11}$ & 35.9 & 0.9979 \\
\hline & \multirow[t]{2}{*}{ II } & Coats-Redfern; $n=1.7$ & 322.6 & $2.3 \times 10^{23}$ & 195.4 & 0.9999 \\
\hline & & Random nucleation & 249.4 & $2.2 \times 10^{17}$ & 80.2 & 0.9924 \\
\hline \multirow[t]{4}{*}{ Bambusa pallida } & \multirow[t]{2}{*}{1} & Coats-Redfern; $n=2.0$ & 194.5 & $2.5 \times 10^{16}$ & 64 & 0.9985 \\
\hline & & Random nucleation & 138.0 & $6.0 \times 10^{10}$ & 43.6 & 0.9871 \\
\hline & \multirow[t]{2}{*}{ II } & Coats-Redfern; $n=1.7$ & 256.9 & $1.1 \times 10^{18}$ & -93.8 & 0.9993 \\
\hline & & Random nucleation & 206.2 & $7.3 \times 10^{13}$ & 13.8 & 0.9962 \\
\hline \multirow[t]{4}{*}{ Dendrocalamus brandisii } & \multirow[t]{2}{*}{ I } & Coats-Redfern; $n=1.9$ & 179.5 & $5.7 \times 10^{14}$ & 32.4 & 0.9978 \\
\hline & & Random nucleation & 128.9 & $4.6 \times 10^{9}$ & 65.1 & 0.9878 \\
\hline & \multirow[t]{2}{*}{ II } & Coats-Redfern; $n=1.6$ & 282.6 & $4.9 \times 10^{19}$ & 125.2 & 0.9994 \\
\hline & & Random nucleation & 233.6 & $5.0 \times 10^{15}$ & 48.8 & 0.9961 \\
\hline \multirow[t]{4}{*}{ Dendrocalamus strictus } & \multirow[t]{2}{*}{ I } & Coats-Redfern; $n=1.0$ & 153.0 & $3.0 \times 10^{11}$ & -30.4 & 0.996 \\
\hline & & Random nucleation & 150.0 & $3.1 \times 10^{11}$ & -12.4 & 0.996 \\
\hline & \multirow[t]{2}{*}{ II } & Coats-Redfern; $n=1.0$ & 311.8 & $1.5 \times 10^{21}$ & 153.4 & 0.9978 \\
\hline & & Random nucleation & 301.8 & $1.7 \times 10^{21}$ & 113.1 & 0.9978 \\
\hline \multirow[t]{4}{*}{ Dendrocalamus hamiltoni } & \multirow[t]{2}{*}{ I } & Coats-Redfern; $n=1.8$ & 181.2 & $6.4 \times 10^{14}$ & 33.3 & 0.9976 \\
\hline & & Random nucleation & 137.2 & $2.7 \times 10^{10}$ & 50.5 & 0.9889 \\
\hline & \multirow[t]{2}{*}{ II } & Coats-Redfern; $n=1.7$ & 301.8 & $3.8 \times 10^{21}$ & 161.4 & 0.9991 \\
\hline & & Random nucleation & 245.3 & $8.7 \times 10^{16}$ & 72.4 & 0.9972 \\
\hline \multirow[t]{4}{*}{ Dendrocalamus gigantus } & \multirow[t]{2}{*}{1} & Coats-Redfern; $n=1.6$ & 172.9 & $1.2 \times 10^{14}$ & 19.6 & 0.9989 \\
\hline & & Random nucleation & 144.7 & $1.9 \times 10^{11}$ & 34.2 & 0.9953 \\
\hline & \multirow[t]{2}{*}{ II } & Coats-Redfern; $n=1.5$ & 241.9 & $1.0 \times 10^{17}$ & 74.1 & 0.9989 \\
\hline & & Random nucleation & 203.7 & $6.6 \times 10^{13}$ & 12.8 & 0.9969 \\
\hline \multirow[t]{4}{*}{ Dendrocalamus membranaceus } & \multirow[t]{2}{*}{1} & Coats-Redfern; $n=1.4$ & 176.3 & $5.7 \times 10^{13}$ & 13.1 & 0.9968 \\
\hline & & Random nucleation & 153.8 & $4.1 \times 10^{11}$ & 27.9 & 0.9949 \\
\hline & \multirow[t]{2}{*}{ II } & Coats-Redfern; $n=1.6$ & 295.1 & $1.0 \times 10^{20}$ & 131.4 & 0.9965 \\
\hline & & Random nucleation & 233.6 & $1.7 \times 10^{15}$ & 39.7 & 0.9886 \\
\hline \multirow[t]{4}{*}{ Bambusa nutans } & \multirow[t]{2}{*}{1} & Coats-Redfern; $n=1.3$ & 189.6 & $9.1 \times 10^{14}$ & 35.7 & 0.9985 \\
\hline & & Random nucleation & 169.6 & $9.9 \times 10^{12}$ & 11.8 & 0.9974 \\
\hline & \multirow[t]{2}{*}{ II } & Coats-Redfern; $n=1.1$ & 240.3 & $1.6 \times 10^{16}$ & 57.9 & 0.9984 \\
\hline & & Random nucleation & 232.8 & $3.4 \times 10^{15}$ & 45.2 & 0.9983 \\
\hline \multirow[t]{4}{*}{ Bambusa bambos } & 1 & Coats-Redfern; $n=1.4$ & 175.4 & $5.7 \times 10^{13}$ & 12.6 & 0.9972 \\
\hline & & Random nucleation & 152.1 & $3.0 \times 10^{11}$ & 30.9 & 0.9957 \\
\hline & II & Coats-Redfern; $n=1.3$ & 261.8 & $7.6 \times 10^{17}$ & 90.3 & 0.9983 \\
\hline & & Random nucleation & 237.8 & $8.4 \times 10^{15}$ & 52.9 & 0.9974 \\
\hline Bambusa vulgaris & 1 & Coats-Redfern; $n=2.0$ & 226.9 & $4.8 \times 10^{19}$ & 126.8 & 0.999 \\
\hline & & Random nucleation & 155.5 & $3.4 \times 10^{12}$ & 10.2 & 0.9907 \\
\hline & II & Coats-Redfern; $n=1.3$ & 429.8 & $4.0 \times 10^{29}$ & 314.5 & 0.9999 \\
\hline & & Random nucleation & 386.6 & $2.0 \times 10^{26}$ & 251.3 & 0.9996 \\
\hline
\end{tabular}


It has been already reported that pyrolysis of cellulose is endothermic while that of wood and lignin is endothermic initially but later becomes exothermic. The endothermic peaks are masked by strong exotherms due to an oxidative atmosphere, maintained in the experiment. Thus, trying to represent the full complexity of the hydrocarbon degradation process makes no sense and we depend upon global pyrolysis kinetics applied to bamboo is used to predict the overall rate of volatiles release (i.e., mass loss) from the solid. For all the samples two decomposition stages are evaluated since, the third stage, if exists, involve a mass loss of less than or equal to $5 \%$. Thus determining kinetic parameters of the third stage is insignificant and process is simply the oxidation of residual char. So the present study concentrates on the first and second decomposition stages of all bamboo samples. For all the twenty decomposition stages of ten bamboo species, the order parameter ranges from $1.0-2.0$. Generally, the first stage of decomposition has higher order parameter compared to the second stage. The highest order parameter (2.0) is found for the first decomposition stage of BP and BV and the lowest for DS (1.0). The correlation coefficient for the first stage and second stage is greater than or equal to 0.9960 and 0.9965 respectively. The kinetic parameters show much higher values for the second stage in comparison with the first stage of decomposition. The activation energy for the primary decomposition stage ranges from 153.0 to $226.9 \mathrm{~kJ} \mathrm{~mol}^{-1}$. The lowest and highest value for energy of activation is found for DS and BV respectively. It is interesting to note that the stability in terms of DTG peak temperature is highest for dendrocalamus strictus (DS), which possess the lowest values for kinetic parameters for the main decomposition stage. The order parameter for both decomposition stages are unity for DS. Entropy of activation for main stage of DS alone is negative and for all other samples it is positive. Positive values of entropy of activation indicates that the activated complexes are less ordered than the corresponding reactants. So, the mass loss reactions are faster than in the normal course. For DS, activation energy for the second stage of decomposition (311.8 $\mathrm{kJ} \mathrm{mol}^{-1}$ ) is about two times higher than that obtained for the first stage $\left(153.0 \mathrm{~kJ} \mathrm{~mol}^{-1}\right)$. This indicates that with comparatively higher energy of activation, DS undergo very fast decomposition with high volatile evolution towards the end of decomposition, once activated. Also, the higher the activation energy, the higher is the sensitivity of Arrhenius parameter to temperature.

The kinetic parameters for the main stage of thermal decomposition are found to be highest for the species, Bambusa vulgaris. The activation energy for the major mass loss stage for the bamboo samples are much lower than the activation energy of pure cellulose (Table 3.2). The activation energy for major mass loss stage of different bamboo species decreases in the order $\mathrm{BV}>\mathrm{BP}>\mathrm{CP}>\mathrm{BN}>\mathrm{DH}>$ $\mathrm{DB}>\mathrm{DM}>\mathrm{BB}>\mathrm{DG}>\mathrm{DS}$. The average activation energy of bamboo samples for the first stage of decomposition, excluding BV and DS, are $183 \pm 11$ $\mathrm{kJ} \mathrm{mol}^{-1}$. BV and DS show large deviation. The order parameter for the second stage of decomposition ranges from 1.0 to 1.7. For the second stage, values of the kinetic parameters are found to be maximum for the species Bambusa vulgaris and the lowest values are obtained for Bambusa nutans. For the second stage of decomposition, entropy of activation is positive for all samples. The average activation energy for the second stage is $\sim 294 \mathrm{~kJ} \mathrm{~mol}^{-1}$.

\section{Mechanism of decomposition}

Mechanism based kinetic equations elucidated by Satava have been employed to determine the mechanism of the decomposition for ten bamboo varieties and FR treated DS samples ${ }^{14}$. The best linear plots obtained for each of the decomposition stages is chosen as the one, corresponding to the correct mechanism of the reaction for a particular decomposition stage. From the values of slope and intercept of the linear plots, the kinetic parameters were calculated and tabulated in Table 2. It is found that the decomposition reactions of all these systems go along with the Mampel equation involving random nucleation with single nucleus on each particle ${ }^{14}$. The kinetic parameters evaluated using these equations are mostly comparable with those utilizing the CoatsRedfern equation. Best fit model for the kinetics of bamboo pyrolysis is still in question as the process of degradation involve catalysis by metal compounds present in the bamboo matrix and the various secondary reactions owing to different physical and chemical characteristics of components such as cellulose, xylan and lignin ${ }^{15}$.

\section{CONCLUSION}

The thermal stability of ten varieties of bamboo of approximately same age and cultivated 
in the same land terrain were compared using simultaneous TG-DTA analysis. The thermochemical conversion reactions are found to be very useful techniques for biomass upgrading. The pyrolysis of lignocellulosic materials primarily involve a polymeric structure breakdown, converting the components into volatiles and char. Based on the thermal stability of species it can be best utilized for commercial purpose.

Thermal stability in terms of first stage of degradation is lowest for BV and higher stability is attributed to DS and DM. The onset temperature for active lignocellulosic pyrolysis for the first mass loss stage is between $220^{\circ} \mathrm{C}-240^{\circ} \mathrm{C}$. DM, BN and BV complete the decomposition process in two distinct stages and all others in three stages. The first stage, dominant below $340^{\circ} \mathrm{C}$, decomposes polymers forming active carbonaceous char which release volatile gases upon increase in temperature leaving approximately $5 \%$ by weight of above $450^{\circ} \mathrm{C}$.

The kinetic parameters were calculated for the mass loss stages during slow decomposition of ten species of bamboo by the Coats-Redfern integral method. The kinetic parameters viz., energy of activation, pre-exponential factor and entropy of activation for the main stage of pyrolysis are found to be highest for BV. The activation energy for major mass loss stage of different bamboo species decreases in the order $\mathrm{BV}>\mathrm{BP}>\mathrm{CP}>\mathrm{BN}>\mathrm{DH}>$ $\mathrm{DB}>\mathrm{DM}>\mathrm{BB}>\mathrm{DG}>\mathrm{DS}$.

The first stage of decomposition has higher order parameter compared to the second stage. For all the twenty decomposition stages of ten bamboo species, the order parameter ranges from 1.0-2.0.
The highest order parameter is found for the first decomposition stage of BP and BV and the lowest for DS. Entropy of activation for main stage of DS alone is negative and for all others it is positive. For the second stage of pyrolysis, entropy of activation is positive for all samples. This indicates that the activated complexes are less ordered than the reactants, and evidently the decomposition reactions are presumed faster.

The decomposition reactions of all these samples obeys the Mampel equation indicating the mechanism of random nucleation with one nucleus on each particle. The kinetic parameters calculated using the equations on the aboveproposed mechanism for the samples are mostly comparable with those calculated using the CoatsRedferm equation.

Global pyrolysis kinetics applied to bamboo can be extended for predicting the overall volatile release rate from the solid and consequently the thermal stability and also shower light upon the mechanistic steps in the thermal degradation process.

\section{ACKNOWLEDGEMENT}

The author gratefully acknowledge with thanks JNTBGRI, Thiruvananthapuram, India for providing the bamboo samples voluntarily and Department of chemistry, University of Kerala for granting access to thermogravimetric facility.

\section{Conflict of interest}

The author declare no conflict of interest.

\section{REFERENCES}

1. Rowell R. M. Wood Mat. Sci. Engg., 2006, 1, $29-33$.

2. Scurlock J.M.O.; Dayton D.C.; Hames B. Biomass and Bioenergy., 2000, 19, 229-244.

3. Antal M.J., Biomass Pyrolysis: A Review of the Literature Part 2 - Lignocellulose Pyrolysis. in K.W. Böer, J.A. Duffie (Eds) Advances in Solar Energy. Springer, Boston., 1985, 175-255.

4. Shafizadeh F., The Chemistry of Pyrolysis and Combustion, in: R. Rowell (Ed), The Chemistry of Solid Wood, American Chemical Society, U.S., 1984, 489-529.

5. Kawamoto H.; Murayama M.; Saka S. J. Wood. Sci., 2003, 49, 469-473.

6. Rowell R.M.; Dietenberger M. A. Thermal Properties, Combustion and Fire Retardancy of wood. in: R. M. Rowell (Ed) Handbook of Wood Chemistry and Wood Composites, CRC press, Boca Raton, FL., 2013, 127-150.
7. Wiedemann H. G. Thermochim. Acta., 1993, 229, 215-228.

8. Amutio M.; Lopez G.; Aguado R.; Artetxe M.; Bilbao J.; Olazar M. Fuel., 2012, 95, 305-311.

9. Lu J. J.; Chen W. Appl. Energy., 2015, 160, $49-57$.

10. Bada S.O.; Falcon R.M.S.; Falcon L.M. Thermochim. Acta., 2014, 589, 207-214.

11. Zehui Jiang; Zhijia Liu; Benhua Fei;Zhiyong Cai; Yan Yu; Xing'e Liu. J. Anal. Appl. Pyrol., 2012, 94, 48-52.

12. Coats A., Redfern J. Nature., 1964, 201, 68-69.

13. Urbanovici E.; Popescu C.; Segal E. J. Therm. Anal. Calorim., 1999, 58, 683-700.

14. Satava V.; Skvara F. J. Am. Cer. Soc., 1969, 52, 591-595.

15. Mui E. L. K.; Cheung W. H.; Lee V. K. C.; McKay G. Ind. Eng. Chem. Res., 2008, 47, 5710-5722. 